\title{
DRAWING AND LANDSCAPE SIMULATION FOR JAPANESE GARDEN BY USING TERRESTRIAL LASER SCANNER
}

\author{
R. Kumazaki ${ }^{\text {a, } * \text {, Y. Kunii }}{ }^{\mathrm{a}}$
}

${ }^{\text {a }}$ ITU, Department of Landscape Architecture Science, Tokyo University of Aguriculture, 1-1-1 Sakuragaoka, Setagaya, Tokyo, 156-8502, Japan - (45715004, y3kunii)@ nodai.ac.jp

\section{Commission V/WG 4}

KEY WORDS: terrestrial laser survey, drawing of ground plan, landscape simulation, extract contour lines

\begin{abstract}
:
Recently, many laser scanners are applied for various measurement fields. This paper investigates that it was useful to use the terrestrial laser scanner in the field of landscape architecture and examined a usage in Japanese garden. As for the use of 3D point cloud data in the Japanese garden, it is the visual use such as the animations. Therefore, some applications of the 3D point cloud data was investigated that are as follows. Firstly, ortho image of the Japanese garden could be outputted for the 3D point cloud data. Secondly, contour lines of the Japanese garden also could be extracted, and drawing was became possible. Consequently, drawing of Japanese garden was realized more efficiency due to achievement of laborsaving. Moreover, operation of the measurement and drawing could be performed without technical skills, and any observers can be operated. Furthermore, 3D point cloud data could be edited, and some landscape simulations that extraction and placement of tree or some objects were became possible. As a result, it can be said that the terrestrial laser scanner will be applied in landscape architecture field more widely.
\end{abstract}

\section{INTRODUCTION}

3D Laser scanner has various kinds. Terrestrial 3D Laser Scanner measure products of the district by install it in the ground. Airborne Laser Survey System checks a shape of the ground altitude and topography precisely by Positional information of a plane distance to the point that a laser reflected back and information of the angle from the GPS, IMU by fire a laser to the ground from the laser scanner which it was equipped by the plane. MMS (Mobile Mapping System) measures a road and neighbouring mosaics $3 \mathrm{D}$ point cloud data by equipped with a digital camera and the laser scanner which were carried by a vehicle. (Kataoka, 2014)(Ishioka, 2009)

As described above, terrestrial laser survey using terrestrial 3D Laser Scanner attracts attention as surveying machinery and tools measuring a shape easily in contract with the objects of the comparative short distance. As a reason for that, it can acquire 3D dimensional shape data for an object because of contactless and high speed (Kunii, 2010). Following are some examples, the extraction of the part of the historic structure. (Ajioka, 2013) The highly precise $3 \mathrm{D}$ modeling of the city. The modeling of the 3D printer with the use of 3D point cloud data. Recently, use of terrestrial 3D laser survey advances mainly in a field of civil engineering, but use study is expected in a field of landscape architecture that perform to record by 3D dimensional shape data. Specifically, it is expected that the use of terrestrial 3D laser survey is effective for the making of the ground plan of the garden, because the surveying by Total Station needs great labour (Awano, 2013).

I left need to find utilization other than visual technique such as computer animation, so as to examine the applicability of terrestrial 3D laser scanner in the garden investigation. In this research, I examined that studied various usefulness of
Terrestrial 3D Laser Scanner in the garden by perform that making of the ground plan with garden from 3D point cloud data.

\section{JAPANESE GAREDENS FOR MEASUREMENTS}

In this research, four Japanese gardens are adopted as measurement sites which are as follows; Taikan Yokoyama Memorial Garden (July, 2013: Taito-ku Tokoy), Mitsuaki Tanaka Old House Garden (August, 2013: Odawara Kanagawa), Saito Family Garden (August, 2014: Ishinomaki Miyagi) and Gokichi Matsumoto Old House Garden (August 2014: Odawara Kanagawa).

Laser measurements for these gardens were performed, and 3D point cloud data was acquired respectively. In addition, these laser measurements were included each own observation which were requested by each owner or local government. The purposes of these observation were maintenance of garden, grasping the present situation and create a new ground plan from past situation.

\section{DRAWING FOR JAPANESE GARDEN BY USING 3D POINT CLOUD DATA}

The point cloud data of Japanese gardens can be obtained by the laser measurements. Especially, in order to drawing of these gardens, the point cloud for ground level are as an important data. However, ground surface of the data were difficult to recognize from above view due to tree crowns (figure 1). Therefore, 3D point cloud data were deleted more than $1 \mathrm{~m}$ and make it possible visibility of ground surface on the state of clouded by tree (figure 2).

\footnotetext{
* Corresponding author. This is useful to know for communication with the appropriate person in cases with more than one author.
} 


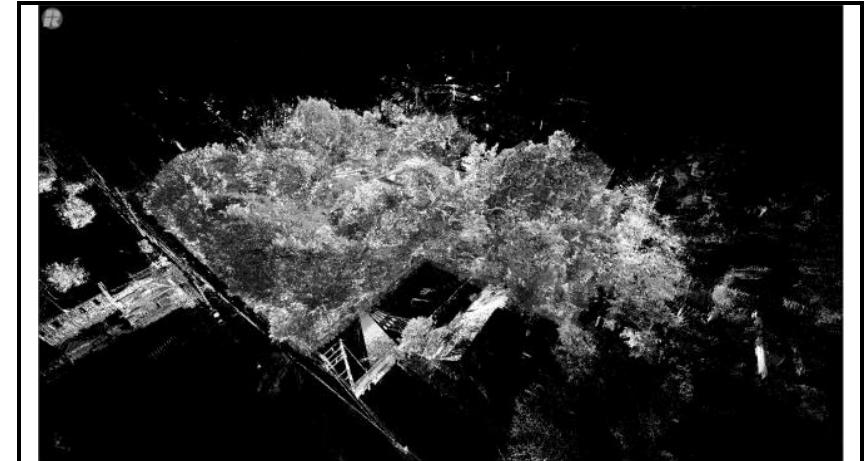

Figure 1.3D point cloud data (whole data)

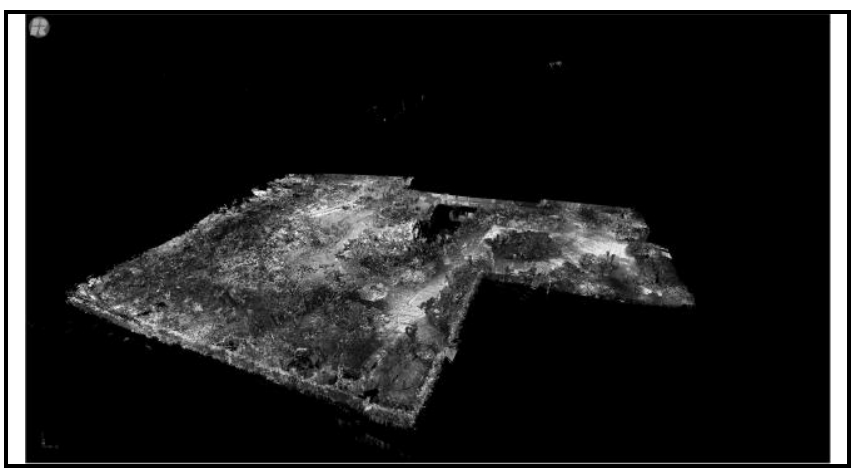

Figure 2.3D point cloud data (delete more than $1 \mathrm{~m}$ data)

\subsection{Create of the Point Density Map}

In order to obtain detail measurement data for ground level, the high density point cloud is required. However, the 3D point cloud data has huge volume due to include useless data, and smooth operations of the point cloud data processing are so difficult. Therefore, 3D point cloud data of each equipment point severally were combined by divide group of various places. After that, all group data were combined, and detail 3D dimensional shape data could be created. These procedures are shown in figure 3 .

\subsection{Output as DXF Format}

DXF format is supported many CAD software, and feature points of the format are easy understanding structure and versatility. Then, point cloud data that deleting useless point was outputted in DXF, and point cloud of ground level became possible to show as ortho image. The ortho image by DXF is shown in figure 4.

\subsection{The Point Density and Scale}

The visualization of the point cloud data is influences the density. Then, suitable point density was considered for scale. Figure 5 shows ground plan of the most high point density.

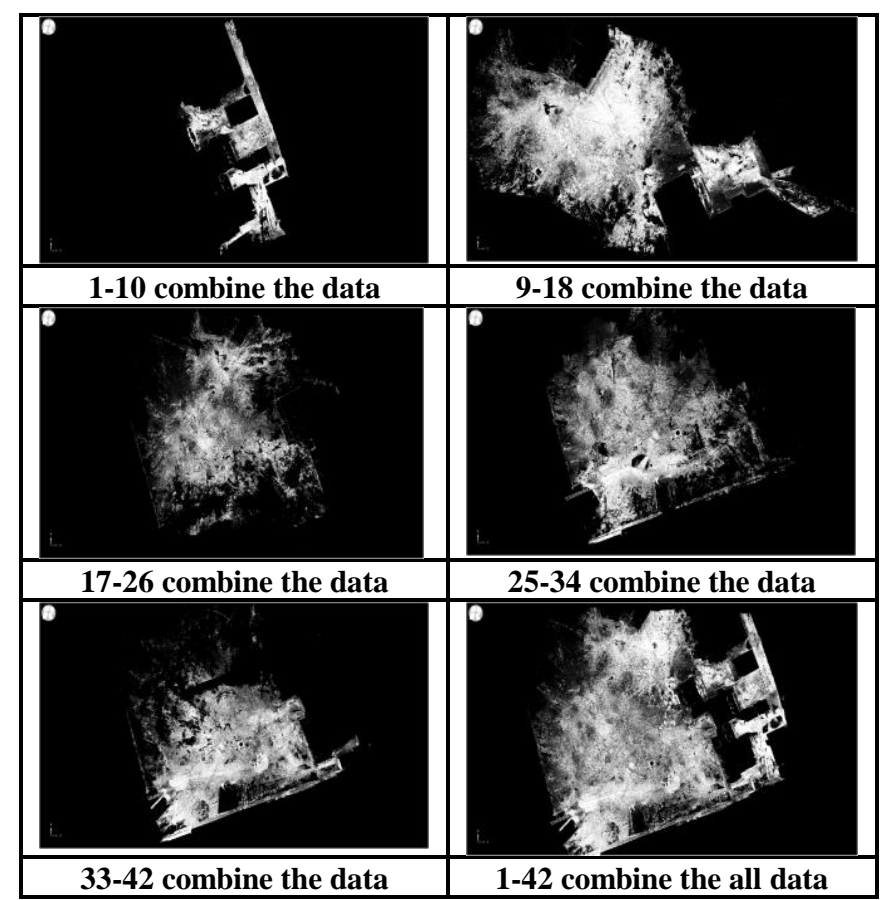

Figure 3 . The point density map of each group

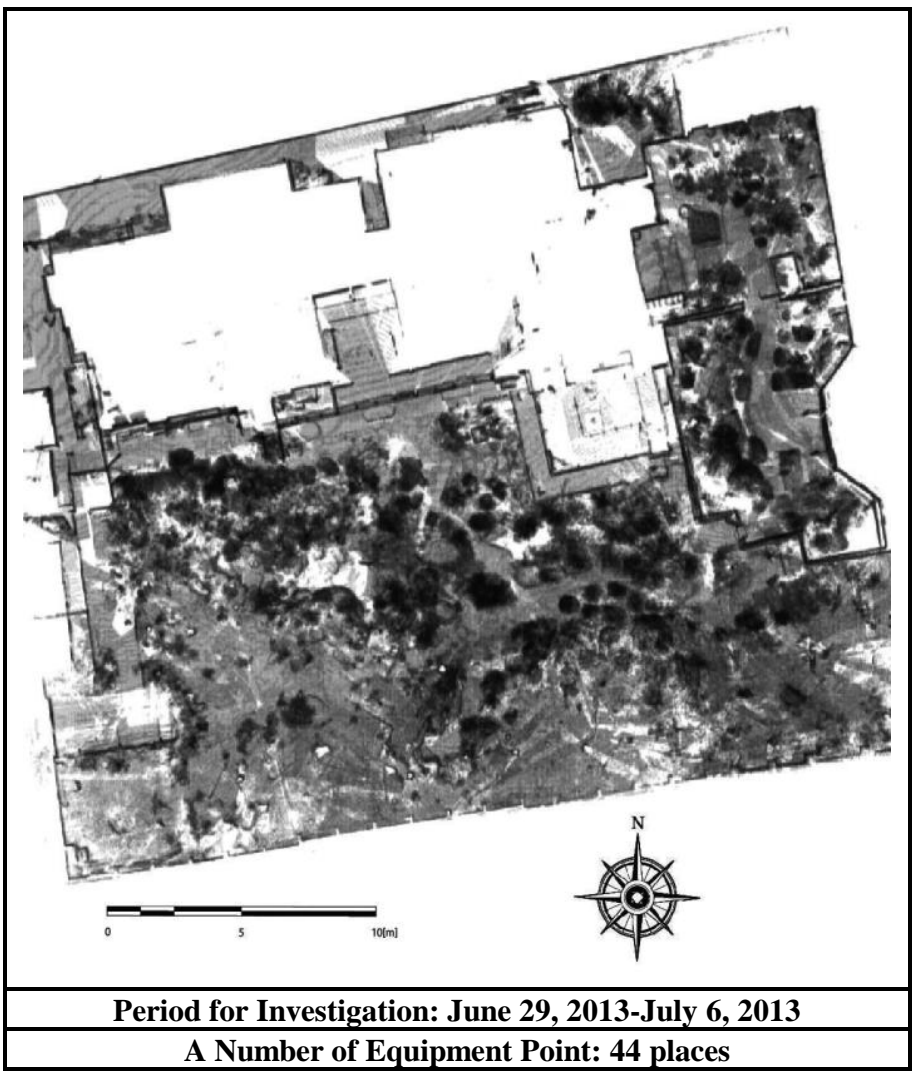

(a) Yokoyama Taikan Memorial Garden (Taito-ku, Tokyo) 

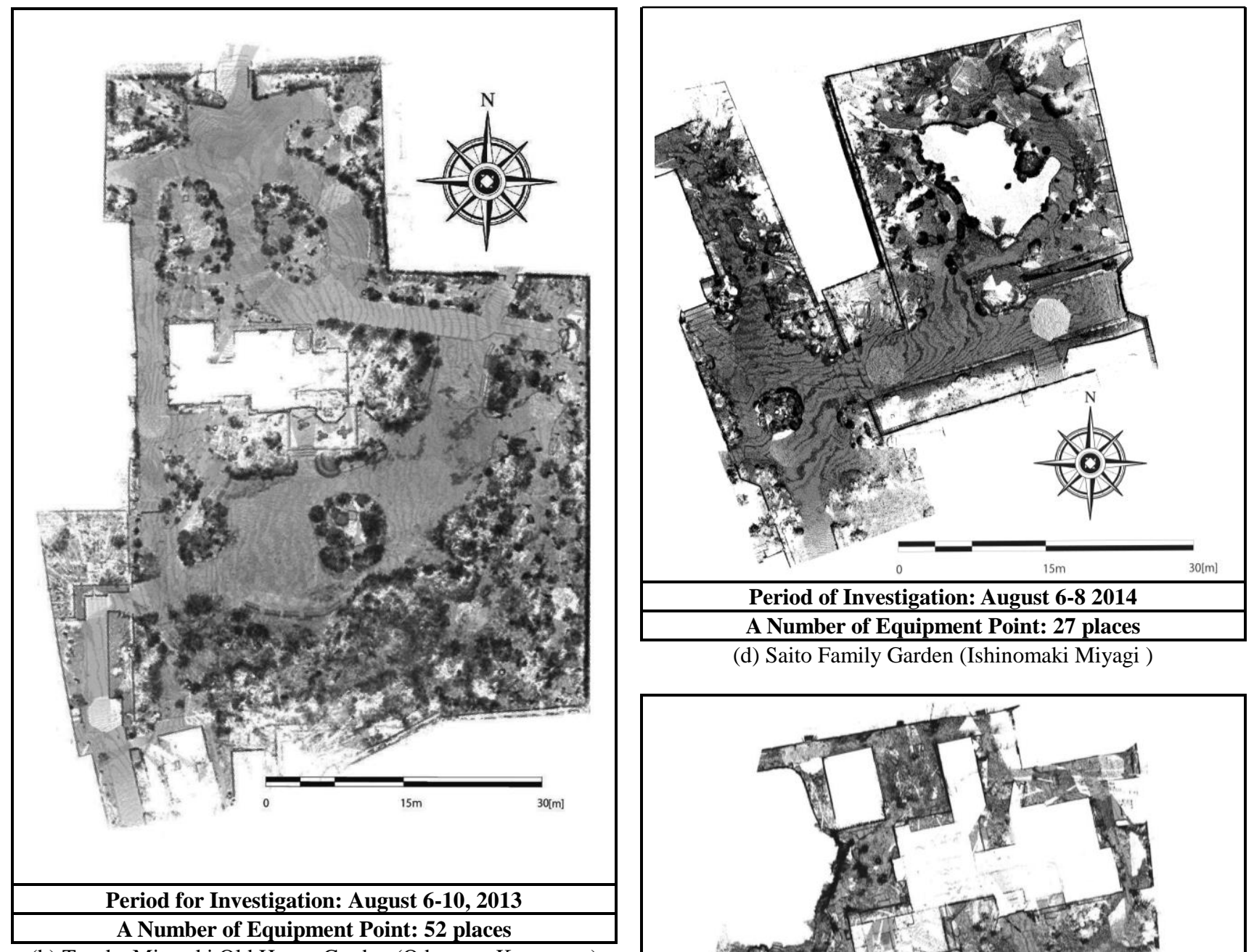

A Number of Equipment Point: 27 places

(d) Saito Family Garden (Ishinomaki Miyagi )

(b) Tanaka Mitsuaki Old House Garden (Odawara, Kanagawa)

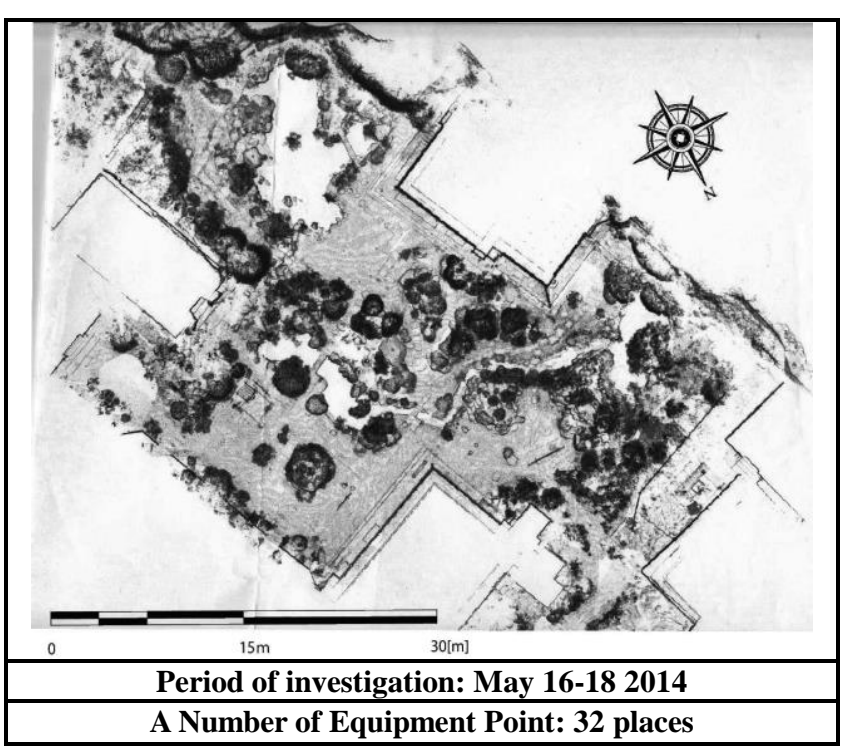

(c) Saito Family Garden (Ishinomaki, Miyagi)

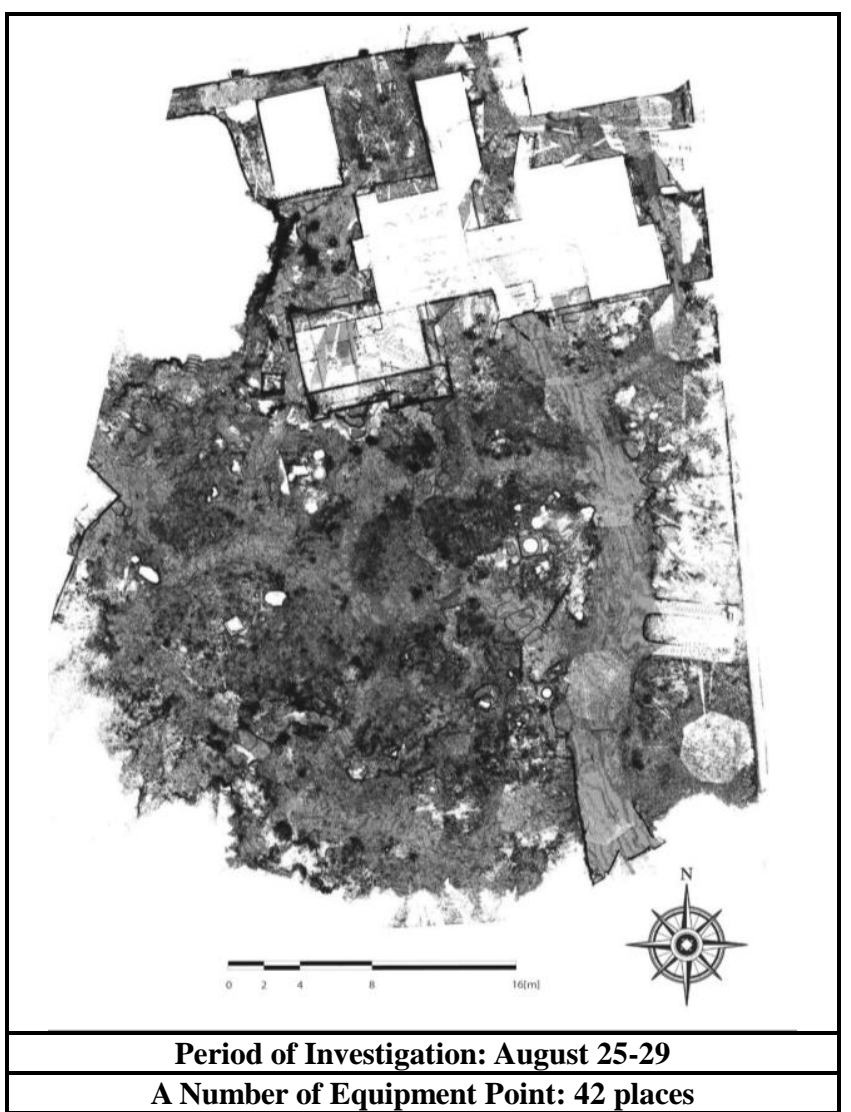

(e) Matsumoto Gokichi Old House Garden (Odawara Kanagawa)

Figure 4. A ground plan of point cloud by outputting orthochromatic images 


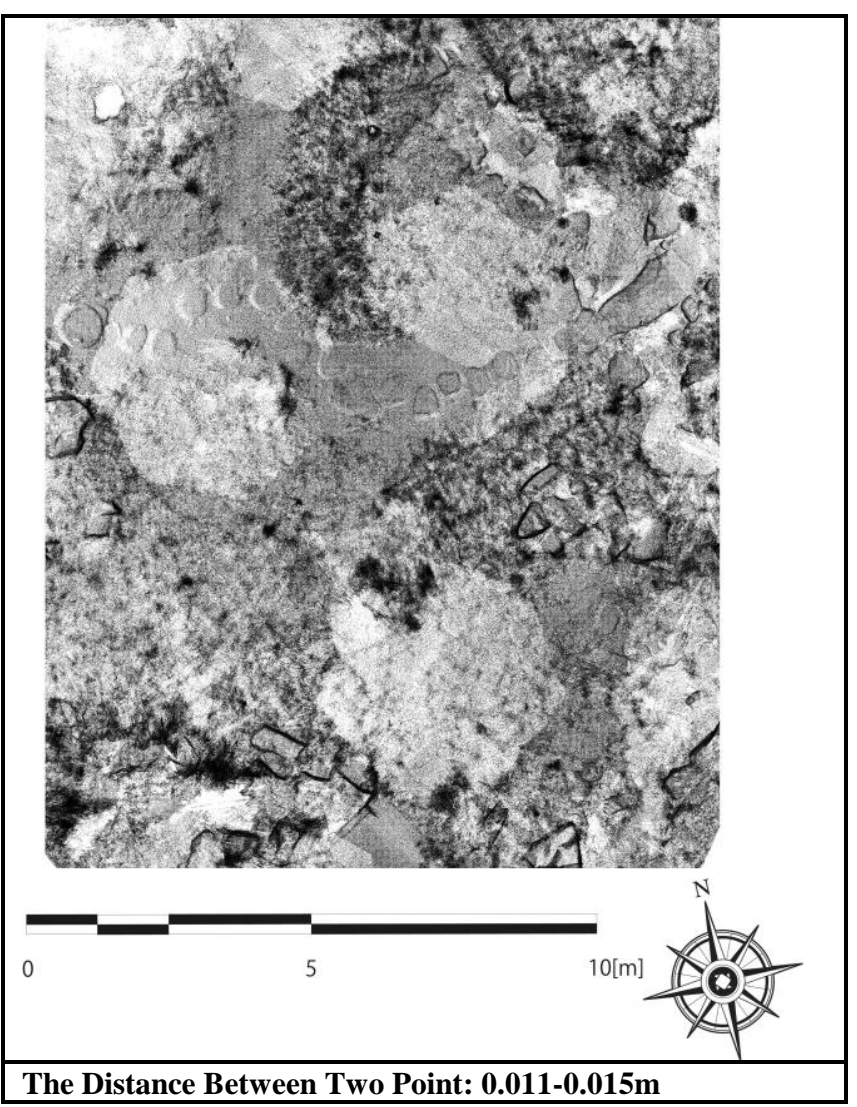

Figure 5. Ground plan of the high point density

\subsection{Drawing of Contour Line}

3.4.1 Classification of height and chose original point: $3 \mathrm{D}$ point cloud data include height information, and it becomes possible to divide each height information. In addition, it is possible to create data that divide height by using the DXF data. In order to draw contour line of each garden, the each height data of Yokoyama Taikan Memorial Garden and Matsumoto Gokichi Old House Garden was extracted by following procedure. Firstly, temporary bench mark was chosen in the field, and the height of temporary bench mark was set as \pm 0 . In this study, position of temporary bench mark was chosen on the end of washbasin (figure 6). Secondly, the height classification data of point cloud was outputted. The height data of Matsumoto Gokichi Old House Garden is shown in figure 7.

Drawing of Contour Line and Crown Projection: From the above procedure, the height classification data were converted layers. In that case, the overlay for each layer was performed by using the temporary bench mark. After that, contour lines were drawn (figure 8). Furthermore, crown projection area of each tree was surveyed in the actual gardens, and these were drawn in ground plan. Figure 9 shows the ground plan of Matsumoto Gokichi Old House Garden by using these information.

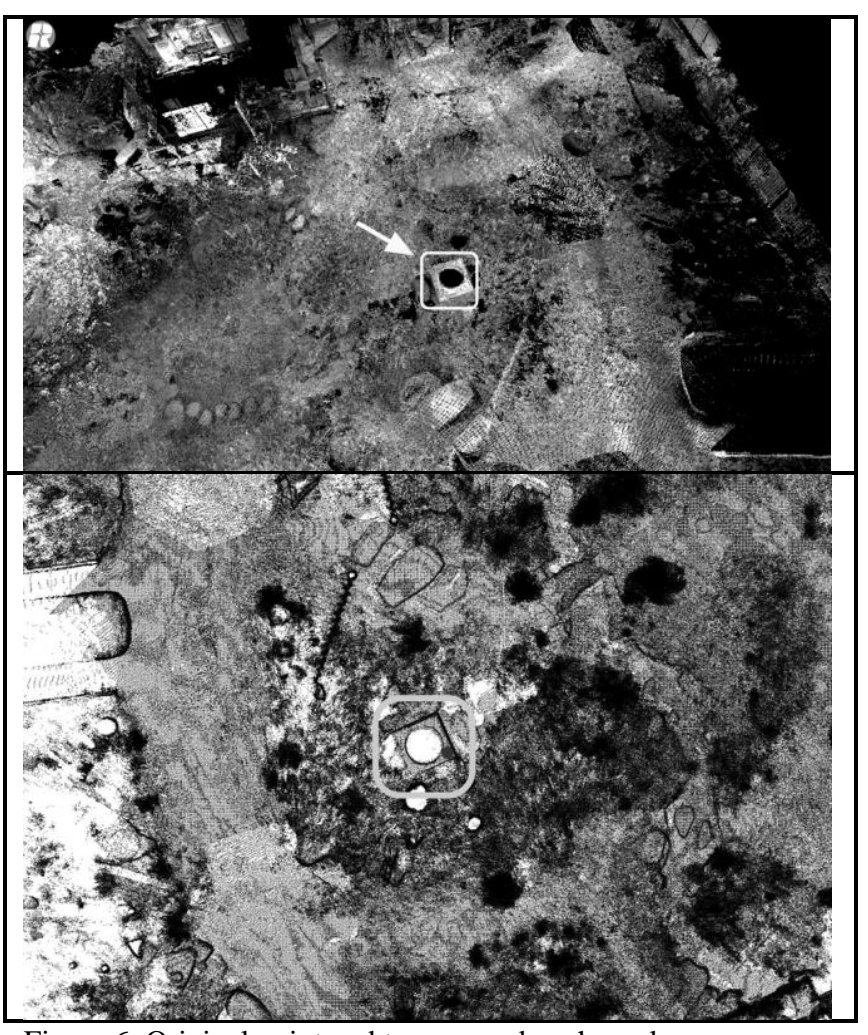

Figure 6. Original point and temporary bench mark

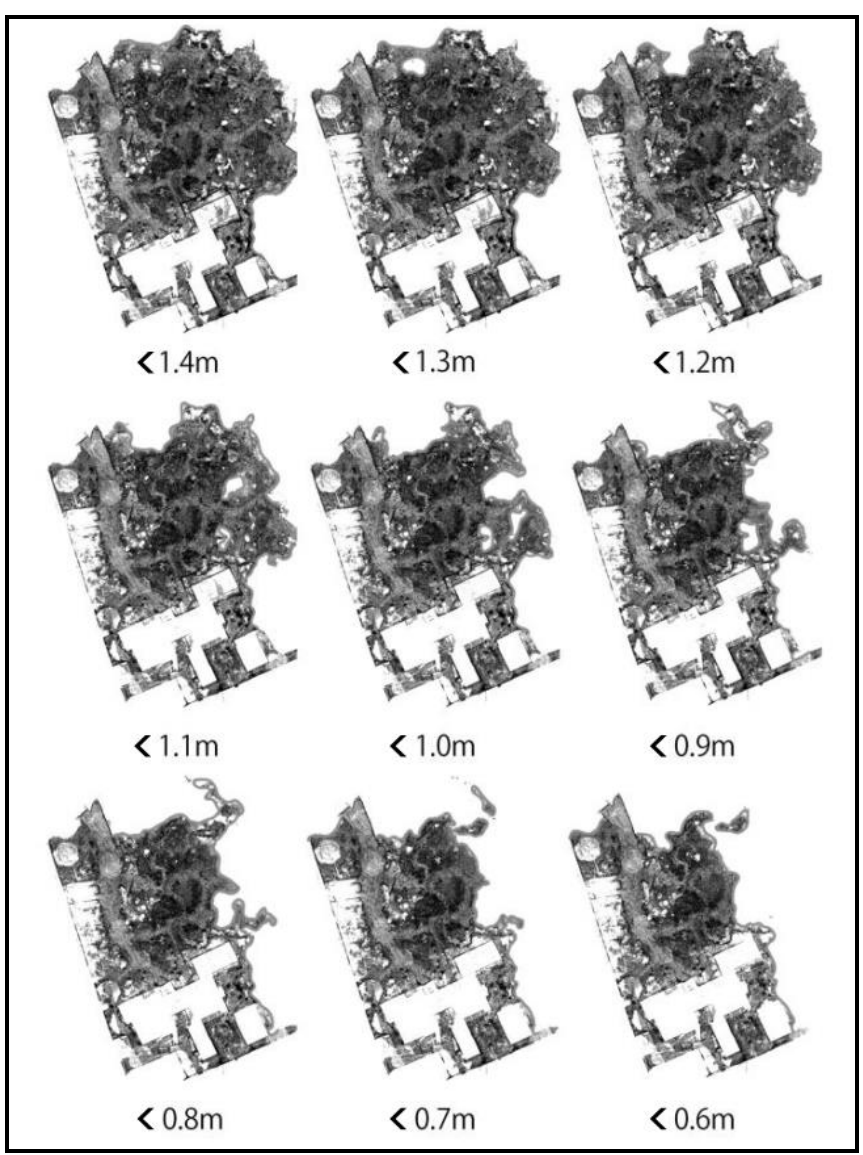

Figure 7. The height classification of Matsumoto Gokichi Old House Garden 


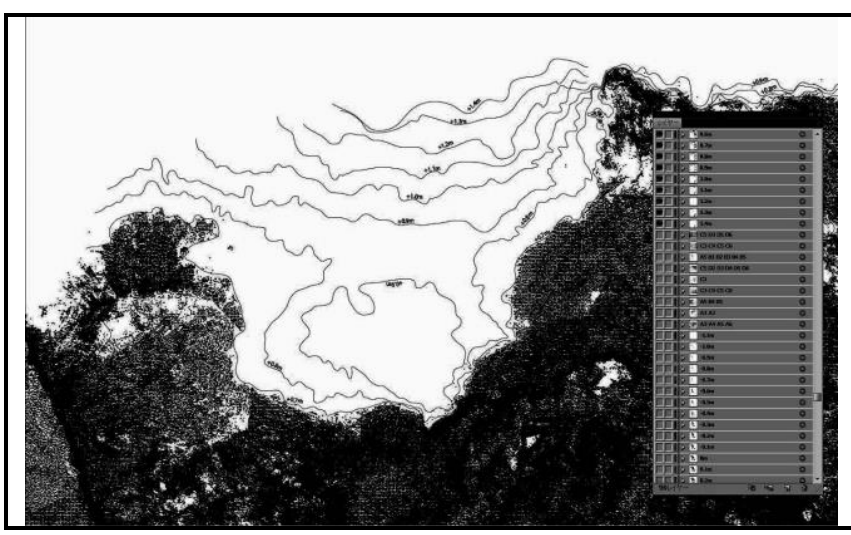

Figure 8. Drawing of contour line

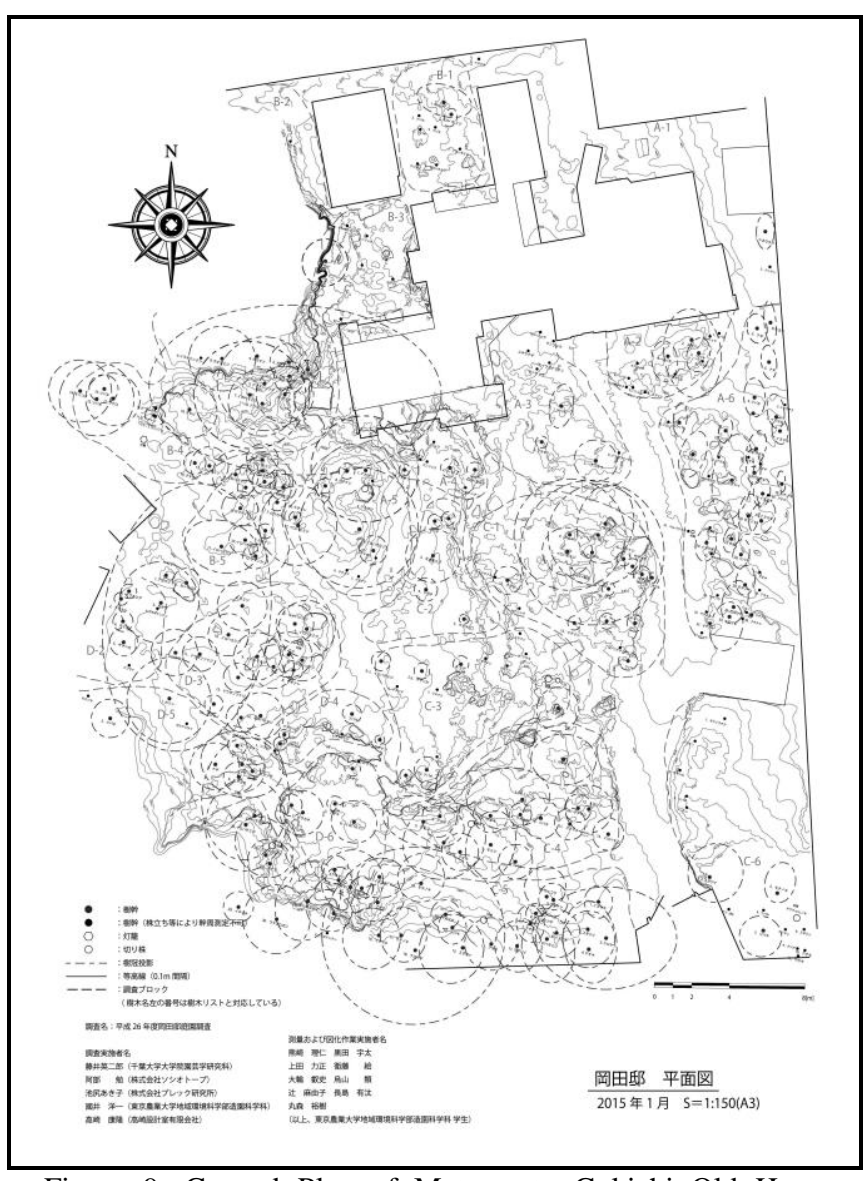

Figure 9. Ground Plan of Matsumoto Gokichi Old House Garden (This is created as part of the surveying project garden)

\section{DATA POCESSING FOR GIVE LANDSCAPE SIMULATION}

\subsection{Landscape Simulation of Cut down Tree}

$3 \mathrm{D}$ point cloud data by survey the field can be used for landscape simulation. In order to simulate, it needs to be delete useless point cloud data that cut down tree of point cloud by virtual 3D visual world. The comparison of before and after of the simulations are shown in figure 10 .

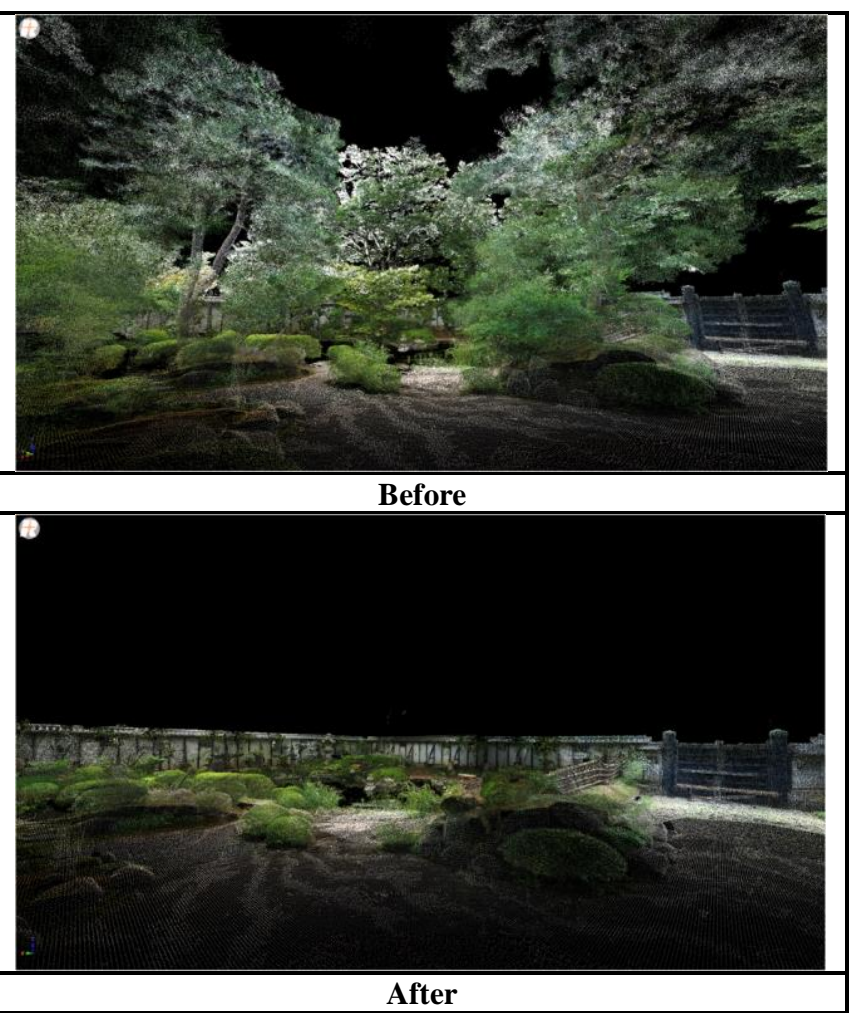

Figure 10. Landscape Simulation of Cutting Trees. (Saito Family Garden)

\subsection{Triangular Mesh Forming and Polygon Model Creation}

3D shape data by measurement are constituted by point cloud data, and objects are shown to transmit. Therefore, the exterior wall of architecture and the trunk of a tree in the garden were desirable to apply constitute the triangular mesh. By doing so, it is become possible to create $3 \mathrm{D}$ model which were much closer to reality (Figure 11).

\subsection{Available Polygon Model}

Figure 11 shows the polygon model of trees that in order to practice landscape simulation. Perform to insert polygon model of Japanese red pine for virtual field of figure 10. Figure 12 shows landscape simulation that insert Japanese red pine of 3D point cloud.

\section{CONCLUSION}

In this study, carried out drawing ground plan at the end series using 3D point cloud data. As a consequence, it is thought that showed one approach describes a method until created ground plan. For example, create ground plan of high point cloud density and extract contour line data of 3D point cloud data by create layer that has been divide height. Also, 3D model of garden consisted by $3 \mathrm{D}$ point cloud data can confirm that simple structure however, it was impossible to confirm the trunk of trees and trees overhang in detail. And with that, attempt to part extract 3D point cloud data of tree, and it is presumed that lead to utilization of create polygon model by using this data. 

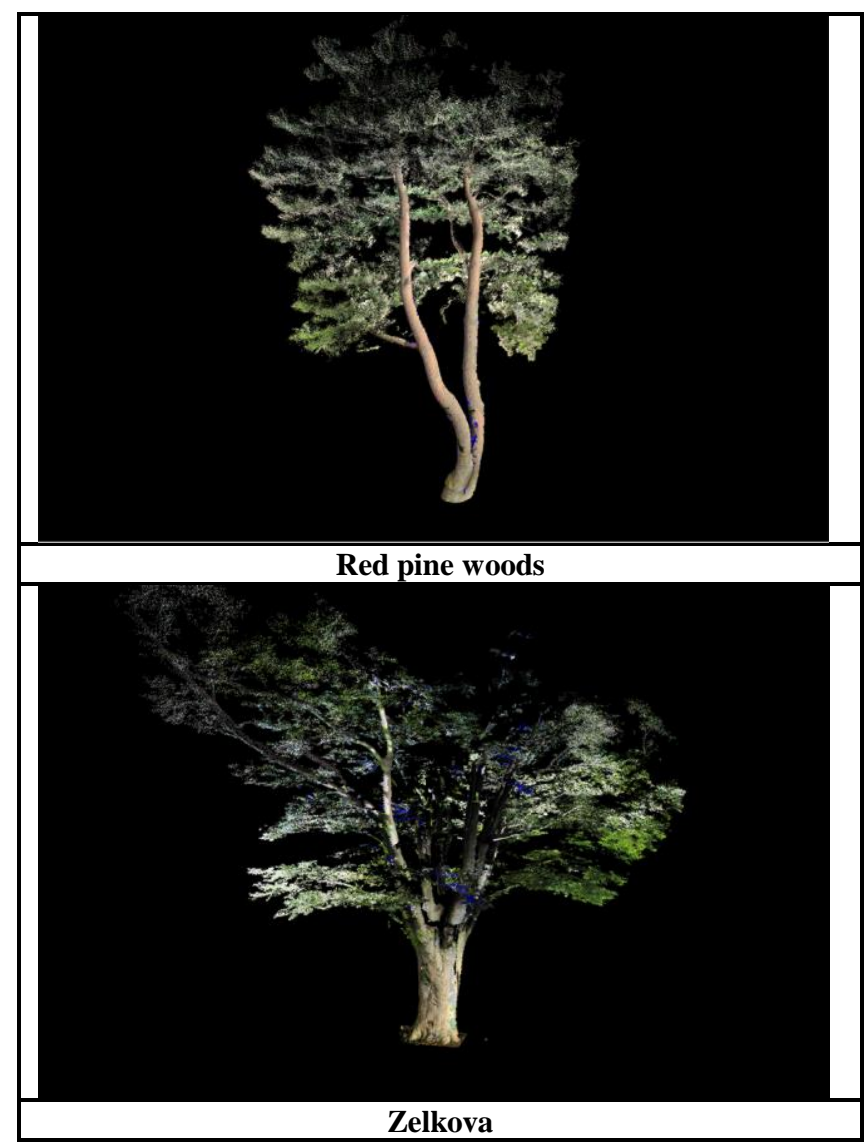

Figure 11.3D model by using point cloud and triangular mesh
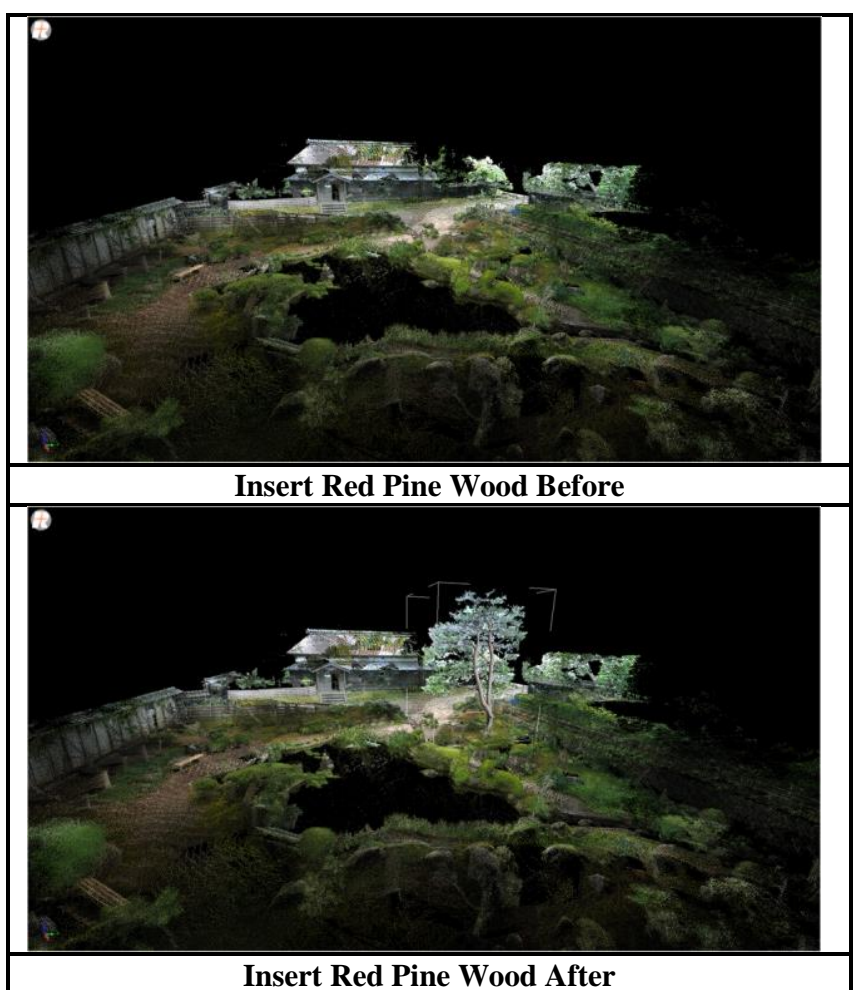

Figure 12. Insert Red Pine Wood on the Saito Family Garden.
The 35th Asian Conference on Remote Sensing (ACRS2014), Naypyitaw, Myanmar

Session G1, OS-239, pp.6, CD-ROM, 2014/10/30

shikawa, K., Amano, Y., Hashizume, T., Takiguchi, J., and Shimizu, S., 2009. City Space 3D Modeling Using a Mobile Mapping System SICE Journal of Control, Measurement, and System Integration Vol.8, No.17, pp.132-139

Kunii, Y., Yanagi, T., Yamazaki, M., 2010.

Grasping of Landscape in Campus by using Terrestorial Laser Scanner and its Application Journal of Agriculture Science, Tokyo University of Agriculture Vol. 55 No.2: pp.199-204 September 2010 Setagaya Tokyo, 156-8502, JAPAN

\section{Awano, T., Kunii Y., 2013}

Survey Technique of Historic Garden by Using 3D and Direct Measurements in the Case Study of Seikan-Tei Garden.

JILA Technical Reports of Landscape Architecture No.7: pp. 126-129

Ajioka, O., Watanabe, H., 2013. Study about possibility of application for making drwings of historical buildings using extracting ridge lines from point cloud

Summaries of technical papers of annual meeting pp. 639-640

\subsection{Acknowledgements}

In this study, really appreciate your kindness for Prof: Makoto Suzuki and Prof: Takashi Awano, each municipality and related organization in illustration of ground plan and field survey. I would like to express my heartfelt thanks.

\subsection{References}

Kataoka, K., Nakagawa, M., 2014.

Evaluation of Projection Model for Random Point Cloud 